\title{
The Impact of International Proficiency Tests on Language Teaching and Motivation: A Case Study
}

\author{
Abdelmoneim Hassan Adam Khamis ${ }^{1}$ \\ ${ }^{1}$ Department of English, College of Arts, University of Bisha, Bisha, Saudi Arabia \\ Correspondence: Abdelmoneim Hassan Adam Khamis, Department of English, College of Arts, University of \\ Bisha, Bisha, Saudi Arabia.
}

Received: August 4, 2019 Accepted: September 2, 2019 Online Published: September 4, 2019

doi: 10.5539/elt.v12n10p14 URL: https://doi.org/10.5539/elt.v12n10p14

\begin{abstract}
This case study of Al-Aqsa School attempts to show that Cambridge Young Learners English Tests (YLE) may hurt learners' motivation and teaching process. The paper aims to highlight the adoption of Cambridge YLE proficiency tests and explore learners and teachers' perception of those tests. Also, providing alternative yardstick measures learners' performance. Combination of a questionnaire, interviews and observation of Cambridge YLE, Movers and Flyers tests were used to collect the data. The evidence presented in this paper suggested that there was a necessity for English language teachers to motivate and prepare pupils of YLE tests at the primary stage. Otherwise, the School should reconsider administering the YLE tests at this fundamental level. The paper recommended progressively institutionalised scholastic accomplishment tests, alongside placement tests at the beginning of the school academic year. The findings should make an essential contribution to the field of applied linguistics and help decision-maker at Al-Aqsa School to take appropriate decisions.
\end{abstract}

Keywords: Cambridge YLE, backwash, proficiency test, achievement test, validity

\section{Introduction}

Set of beliefs about international proficiency tests may have negatively affect language teaching and learning processes, and learners' motivation. Some educators believe that those tests are objective, neutrals, standardised and yardstick of measuring learners' abilities and teachers' levels of qualification at the same time. This investigation is an attempt to highlight that mindset. The way of thinking that determines teachers' teaching and demotivates learner to learn the English language. The focus on teaching test techniques becomes an end in itself, to enable pupils to obtain high marks. Teachers are still being the dispensers of knowledge instead of becoming facilitators, guides and consultants, who create a learning environment. This study is an effort to draw the attention of the educationists, who hold the decisions. The top-down approach of Al-Aqsa School ignores achievement tests and creates another assessment mechanism, Cambridge YLE Tests (Cambridge Assessment). This dramatic shift results in demotivating pupils and puts high pressure on teachers' work. Decision holders should consider the environment that conducive to teaching and learning processes.

\subsection{Statement of the Problem}

The old mindset is that international proficiency tests of English language are perfect standardised, objective and neutral. Moreover, proficiency tests are real diagnostic of both; teachers and learners' actual level. If an individual passes an English proficiency test, he will be ownership of the English language. Those tests have negative aspects to young learners as well as dominating the teaching process. Teachers are still retaining as the dispensers of knowledge. They concentrate on the tests techniques and the correct form of the language instead of creating an environment that stimulates learning.

\subsection{Aims}

1) To highlight the harmful backwash of the international proficiency tests.

2) To identify teachers' and children's attitudes towards the adoption of international proficiency tests.

3) To change the mindset about international proficiency tests to young learners.

\subsection{Questions}

1) To what extent international proficiency tests affect language teaching? 
2) To what extent do the international proficiency tests demotivate children?

3) Why do the schools adopt international proficiency tests at the primary stage?

\subsection{Hypotheses}

1) International proficiency tests may have negative backwash.

2) International proficiency tests may be harmful to young learner's experiences.

3) Schools are adopting international proficiency tests as diagnostic tests.

\subsection{Significance of the Study}

In the Saudi context, no similar study has been conducted to investigate the harmful backwash of the international proficiency tests on language teaching and learners' motivation at Saudi primary schools. Some researchers argued that backwash could be harmful or beneficial. This study bridges the gap in previous research. This analysis will contribute to the fields of applied linguistics and education, in general. The finding will decisively help teachers and inspectors. Decision-makers may find relevant points to their decisions.

\subsection{Research Methodology}

The researcher used a critical, analytical and descriptive approach. The instrument of data collection was a combination of a questionnaire, interviews, and observation of Cambridge Young Learners English (YLE) Tests: Movers and Flyers tests. Those tests took place in 2014 spring.

\subsection{Delimitation of the Study}

This case study explored micro context; primary stage grade fifth and sixth, Al-Aqsa School, Jeddah, KSA. It investigated the institution's culture in testing the English language through YLE tests. The finding could not be generalised to other schools, which had been adopting YLE tests. Therefore, the generalizability was confined.

\section{Literature Review}

\subsection{Testing}

Testing or evaluation is an integral part of learning in any course, syllabus or teaching program. Testing and teaching are so thoroughly interconnected that it is virtually impossible to work in either field without being concerned continuously with each other. According to Karrar (2007), tests may be constructed primarily as devices to reinforce learning and to motivate the learners, or primarily as a means of assessing the learners' performing in the language. In the reinforcing case, the test gears to the teaching that has taken place, whereas in the latter case, the teaching is often geared mostly to test [backwash effect]. It could be said that testing is to measure the reliability and validity of the test. Brown and Abeywickrama (2004) have defined a test as " $a$ method of measuring a person's ability, knowledge or performance in the given domain."

Ingram (1968) stated that "the theme is language testing needs. So far, language testers have concentrated on meeting the need of reducing educational waste-age by developing aptitude and proficiency tests." Aptitude tests determine an individual's propensity to be successful in a given activity. Aptitude tests assume that an individual has inherent strength and weakness. An aptitude test does not test knowledge; it is not a test that one can study for (investopedia.com). Language learning aptitude is a complicated matter, consisting of such factors as intelligence, age, motivation, memory, phonological sensitivity and sensitivity to grammatical patterning. On the other hand, Proficiency Tests measure the overall abilities of individual learners. They are tests in no way related to any syllabus or teaching program.

\subsection{Proficiency Tests vs Achievement Tests}

Both proficiency and achievement tests were concerned with measuring learners' ability at a specific time. In terms of time and money, tests cost time and money. An achievement test is based on syllabus or textbook, whereas proficiency test is not related to any curriculum or course. Moreover, content validity is the main feature of attainment tests; however, proficiency tests lack it.

In general, proficiency tests give a broad picture rather than assessing learners' progress. They do not confer an accurate portrait of how well some learners could do in certain situations. Harmer (2007) cited in many educators, claimed that 'sudden death' testing because learners got 'one-shot' to show how much they know about language. Those tests do not base on a textbook, i.e., IELTS, TOEFL and Cambridge Young Learners English (YLE) Tests: Starters, Movers and Flyers. IELTS and TOEFL are useful tests when selecting people for a particular program because they are designed to differentiate among the test taker. Siddiek (2011) inserts that language education is a business itself as it may be seen in IELTS and TOEFL tests all over the world. 
Educators have divided achievement or attainment assessments into formative and summative tests. The former is carried out during a course of instruction and aimed at providing continuous feedback to both the teacher and learners. It also referred to as educative assessment, which is used to aid learning. In an educational setting, a teacher and learner might provide feedback on learner's work. This feedback might not be used for grading purposes. They are diagnostic for learning. The latter is carried out at the end of a course of education. It measures "sums-up" how much a learner has learned from a course? It is usually a graded test, which marks according to a scale. It is evaluative_evaluation of learning and teaching methods at the same time.

\subsection{Backwash}

The term backwash or wash-back has been defined as the positive or negative impact of a test on classroom teaching and learning process. The problem of backwash is commonplace that testing does not take place in a vacuum. Adverse effects yield bad results on teaching and learning processes. Unfairness, lack of content validity, and incomprehensibility alongside wrong ways of the rating of tests are considered factors that generate negative influence on learners, teachers, parents and decision-makers (Siddiek, 2010a). Alghamdi (2006) suggested that the mismatch between test requirements and teaching program would result in both teachers and students operating with different priorities and goals. The rebounds of a test-teaching mismatch are often described as "Back-wash" and might be positive/negative. When success or failure is the key to the next step in the academic chain, proficiency testing in higher education context will be truly high stakes. If a test has been necessary, the preparation for it will come to dominate all teaching and the learning activities; that is the backwash. Hughes (2003) argued that harmful backwash occurred when test content and testing techniques were at variance with the objectives of the syllabus. In other words, if learners follow a particular English course, that is meant to train them in the language skills, and the test based on no purpose in mind, the backwash will be harmful more than beneficial. International proficiency tests can be divided into general criteria and on purpose tests.

\subsection{Constructing Validity}

Constructing validity has been the most crucial consideration in any test development. Educators define the validity of a test as the test should test what ought to be to measure. A test's validity determines the reliability of its results. Most of the language testers have come to some type of agreement that good test should have validity, reliability, comprehensiveness, practicality and positive backwash (Siddiek, 2010a). The validity of a test should answer these questions:

a) Is the test assessing what is intended to measure?

b) Are the test items based on stated objectives?

c) Are the test items adequately constructed?

Validity might be divided into two types, face validity and content validity. Face validity referred to if a test items look right to other testers, teachers, and testees. In contrast, content validity is a representative sample of the particular syllabus. The content validity is more important than the former. Thus, a test may have face validity as judged by an expert in the field, but may not have content validity for teachers and testers who have taught a particular syllabus.

\subsection{Content Validity}

The functional content of a test should be carefully selected based on the course syllabus. This selection is only logic and fair. The language content of the test should go outside the program only when it is not significant in the exercise or task; i.e., in a reading comprehension test, where the learners may have been encouraged to ignore incidental language they do not know or to guess its meaning from context. The content validity depends on a careful analysis of the language that is being tested and of the particular course objectives. The test should be constructed to cover a representing sample of a programme of study, the relationship between the test items and the programme objectives always being apparent (Siddiek, 2010b).

Bentley (2015) writes, "All teachers are aware of the challenges in [assessing] learners' progress, but CLIL has its challenges because it aims to teach both content and language. In many countries, CLIL approaches are quite new, and some teachers are unsure of what, how and when to assess. Should it be content, language, or both?" According to Bentley, content and language integrated learning (CLIL) measure syllabus content and the language at the same time. He points out that formative tests are performance assessments, and summative tests are standardised and diagnostic tests. These tests pull teachers to rethink their teaching methods and approaches, which are used. 


\subsection{Motivation}

Motivation is an essential element of success. It is an internal drive which pushes individual to do things to achieve something. Broussard (2016), in his project, quotes Ryun's (n.d.) words: "Motivation is what gets you started. Habit is what keeps [an individual] going." Self-Determination Theory (SDT) divides motivation into extrinsic and intrinsic motivation. Extrinsic motivation is the result of outside factors such as the need to pass an exam or a test, the hope of financial reward. The external sources of motivation may be a person's goal/s, person's society s/he lives in, the people around him/her, and his/her curiosity. In contrast, intrinsic motivation comes from within the individual. S/he may be motivated by the enjoyment of the learning process itself or by a desire to make herself/himself feel good (Harmer, 2007).

\subsection{Previous Studies}

Research shows that general and academic proficiency tests did not have content validity. Both were designed to test persons' overall ability. They were not limited to any course, syllabus or a single skill in the language. They had considerable influence over the teaching method and content of language courses. Their backwash might be harmful or beneficial too. People who took these tests experienced fear test. The fear test was the fear of unknown something, which would determine and shape people's future.

Harmer (2007); Hughes (2003); Karrar (2007) \& Siddiek (2010a) emphasised that proficiency tests have a profound backwash effect. Siddiek argued that most of the teaching focused on the techniques of examination rather than doing real education. Karrar concluded that numerous testing techniques still emphasise the negative aspects of language learning, encouraging teachers and students to place more emphasis on correctness than on communicative aspects of language learning. Hughes pointed to backwash need not always was harmful; it could be positively beneficial. Harmer inserted that the backwash effect preoccupied test designers and teachers alike. That fact since teachers quite reasonably wanted their students to pass the exam or the test. The test and the items that were in it dominated their teaching. The question, which was posed itself, if a test based on no course in mind, how teaching would be like? The answer was chaotic and random hypotheses about what would come in the trial.

Hughes (2003) assumed: "Many language teachers harbour a deep mistrust of tests and testers". They kept in their mind that those tests were:

a) A great deal of language testing was inadequate.

b) Language testing often hurt the teaching and learning process.

c) Language testing provided inaccurate information about learners' abilities.

Hughes believed that some widely used international proficiency tests were more harmful than beneficial. The emphasis would be on interpretation rather than on calculation of grades. It might be argued that to base test items on objectives rather than course content was unfair to pupils.

Recently in 2010 spring, a study conducted in Sudan found that Sudan School Certificate (SSC) English Examinations in their recent form were proficiency test rather than scholastic standardised achievement examinations. They were incomprehensive and lacked content validity. Consequently, they had negative backwash in language education development (Siddiek, 2012). Teachers focused on teaching examination techniques rather than did real teaching from the textbooks in their classrooms. It had been discussed that standardised scholastic examinations intended to test specific skills and language elements rather than to test the overall language abilities of these young learners. Siddiek cited in Marshall (1984) put it, "we are likely to structure tests and examinations that will answer our questions and not just give a list of marks to satisfy the school authorities and parents" (2012).

A study was conducted at Al-Aqsa Schools in Jeddah, KSA by Alfaki \& Khamis (2014) found that learners' motivation to learn the English language was low. About $71.1 \%$ of respondents agreed that students' motivation was low. Teachers encountered a difficult challenge on how to motivate their learners to love and acquire the English language. Psychological barriers, such as preconceived ideas about the English language, in contrast to their culture (Arabic Culture), made mental barriers to acquiring the foreign language. According to Krashen's (1987), the Affective Filter Hypothesis, when the filter "UP", it will hinder language acquisition. However, a learner who has strong self-confidence, a good self-image, high motivation, and "a low level of anxiety are better equipped for success in second language acquisition, (Liu, 2017)."

Harmer (2007) cited in Williams and Burden (1997). They went on to point out that, motivation would depend on how much value the individual placed on the outcome s/he wished to achieve. Young learners' motivation was 
often more shapeless and less comfortable to describe. Adults, on the other hand, had clearly defined or vague goals. The new conceptualisation of SDT (Deci \& Ryan, 2008) classifies motivation into controlled and autonomous motivation. Controlled drive presents outside factors, which enable an individual to receive external rewards or to avoid constraints while autonomous inspiration is not the same as intrinsic motivation. Autonomous motivation encompasses extrinsic motivation to become a form of autonomous motivation [internal drive]. Controlled motivation is more fragile and presents risks for well-being than autonomous one (Ali, 2019).

According to Khan (2011), he confirmed that the English language did not enjoy an essential place in the curriculum in KSA as in most developing countries. Despite good infrastructure and qualified teachers, the teaching-learning process seemed to be futile when the actual skill development was not up to the mark. Both the teachers and learners faced socio-cultural and psychological encounters. Teachers' challenges were due to their training as an EFL teacher, experience as a bilingual teacher (in Arabic context), the status of English, the psychology of the learners, language policy, methods and strategies, and assessment_system. Learners faced challenges mainly due to lack of proper motivation, attitude, techniques of teaching, stricter evaluation system, workload. Al-Seghayer (2014) supposed that English teachers proficiency same as inadequate preparation of English teachers, so teacher training and development needed to be seriously considered.

Decentralisation of Saudi School Certificate has brought some complication at the local and international level. The decentralisation resulted in the creation of another assessment measurement called "Qiyas" (Note 1), which led to further complication and dissatisfaction of students as well as teachers. The "Qiyas" provided a proficiency test rather than an achievement test. It lacked content validity, which was considered the main feature in the standardised scholastic achievement language test (Siddiek, 2012). He argued that Qiyas proficiency test neither tested competence nor told about the degree of achievement in the course, which the learner spent twelve years to achieve in general education. He added that "a language proficiency test does not presuppose mastering specific details of a certain syllabus or specific content, because it tests the overall abilities of the learner's language skills" (2012).

Hughes differentiates between general proficiency tests and academic proficiency tests. Therefore, there were two definitions of the word "proficiency". General proficiency tests did not have any occupation or course study in mind. They should have detailed specifications saying just what it was that successful candidates would have demonstrated and could do. It was not a matter if a testee passed or failed on the test. For those tests, "the concept of proficiency was more general". British examples of those tests would be:

1) Cambridge examination (First Certificate \& Proficiency Examinations)

2) Oxford EFL examinations (Preliminary \& Higher)

3) Cambridge YLE (Starters, Movers \& Flyers)

The function of those three examples tests was to show whether nominees reached a certain standard concerning particular specified abilities. Teachers and pupils could judge whether the test was suitable for them, and could interpret test results. "It is not enough to have a vague notion of proficiency, however prestigious the testing body concerned" (Hughes, 2003).

Academic proficiency tests were designed to test people's ability in a language regardless of any language learning background they might have had. Their content was not limited to any language course. In that case, proficient was meant, having sufficient command of the language for a particular purpose. Examples of these tests would be academic IELTS or TOEFL for following a course of study or admission for high education at British and US universities.

\section{Method of the Research}

This case study presents the research methods followed by the researcher to achieve the objectives of this study.

\subsection{Subjects}

The population used in this study was chosen purposively from fifth and sixth grade, primary stage at Al-Aqsa School, Jeddah, KSA. They were 454 pupils and their seven English language instructors. The total number of pupils was 474 . Twenty pupils absented. There was no retest for the absences.

\subsection{Instrument}

A mixed-methods approach was adopted with multiple data-collection. This case study was the critical, analytic and descriptive strategy. A questionnaire was designed to reflect pupils' opinions about YLE; English instructors were interviewed. The observation of tests processes was documented. Both the survey and the interviews included three items. The survey's questions included the difficulty of the exam, easiness of exam and 
preparation for the exam to attain the objectives and the aims of the study.

\subsection{Validity}

The researcher had worked at Al-Aqsa School for eight years as an English language teacher, and he conducted a pilot survey and interviewed English language teachers of fifth and sixth grades in May 2014 spring. The survey included three elements to explore pupils' opinions concerning Cambridge YLE tests and teachers' point of view about these tests. In light of the survey and the teachers' comments, the researcher made some modifications of the questionnaire's questions.

\subsection{Reliability}

The researcher administrated the questionnaire to 454 pupils and interviewed seven English language instructors. To ensure the reliability of the questionnaire, the researcher designed a calculated Pearson Correlation Coefficient. The Pearson Correlation between the two-fold respondents was 0.875966317 , which meant that the questionnaire was reliable.

\subsection{Procedures}

1) After the YLE tests had taken place for 25 days (23/4 - 9/5/2014). The questionnaire administrated during academic days. Pupils responded by putting a tick in the appropriate space opposite to an item in one of the following choices: Agree, Neutral and Disagree. These responses were given values like 1, 2, and 3.

2) The researcher interviewed the teachers on different days. Teachers responded to three questions orally. The researcher documented their answers for later stages.

3) The oral tests were observed while the YLE tests were taking place and the researcher as a coordinator jotted down his observations concerning the YLE.

\section{Data Analysis}

\subsection{Learners' Questionnaire}

Learners' questionnaire translated into pupils' mother tongue (L1) (see Appendix B). The researcher managed survey during the classes, and the instructions were given orally in the pupils' mother tongue. The participants were 454 pupils, namely fifth \& sixth grades. Table 1 shows the statistics and the questionnaire's statements.

Table 1. Learners' questionnaire

\begin{tabular}{llll}
\hline & Agree & Neutral & Disagree \\
\hline Frequency & Cambridge & YLE, the written test was easy. \\
value & 131 & 183 & 140 \\
Percentage & 131 & 366 & 420 \\
& $28.9 \%$ & $40.3 \%$ & $30.8 \%$ \\
Frequency & Cambridge YLE, the oral test was easy. & \\
Value & 256 & 114 & 84 \\
Percentage & 256 & 228 & 252 \\
& $56.4 \%$ & $25.1 \%$ & $18.5 \%$ \\
Frequency & I was ready for Cambridge YLE Tests. & 101 \\
Value & 241 & 112 & 353 \\
\hline Percentage & 241 & 224 & $\mathbf{2 2 . 2 \%}$ \\
\hline
\end{tabular}

Note. Table 1 presents both Movers and Flyers tests.

Table 1 shows statistics of learners' questionnaire. About $30.8 \%$ of the pupils disagreed with statement $1,18.5 \%$, of them, disagreed with statement 2 and $22.2 \%$ of the respondents disagreed with statement 3 . Roughly $40.3 \%$, $25.1 \%$, and $24.7 \%$ of the responses were neutral. They did not decide whether YLE tests were easy or difficult. 
Table 2. $6^{\text {th }}$ Grade

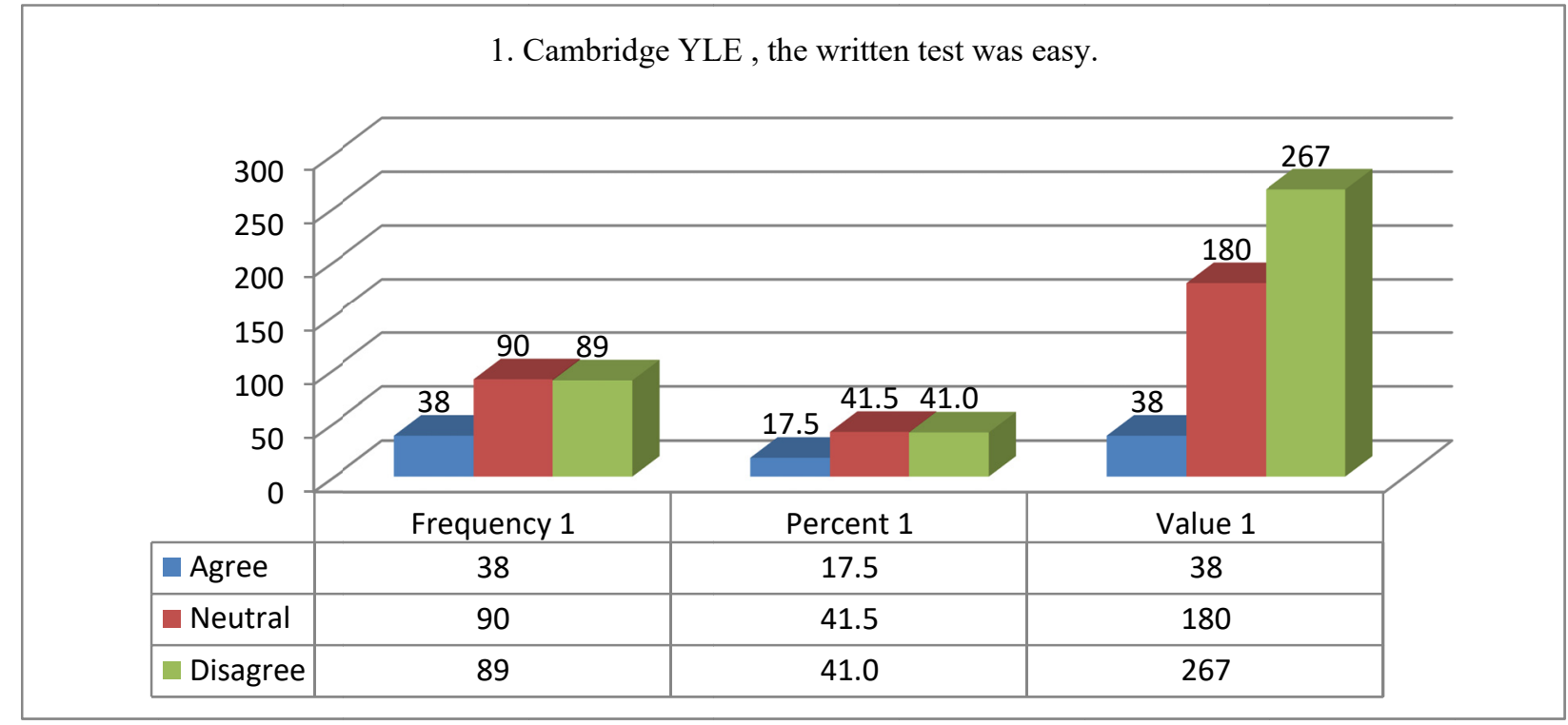

Table $26^{\text {th }}$ Grade shows that about 17\% of YLE responses agreed; the written test was easy. Eight-nine responses were not satisfied, and ninety responses were neutral. Both neutral \& disagree responses represented about $81.5 \%$ of the numbers of the pupils.

Table 3. $6^{\text {th }}$ Grade

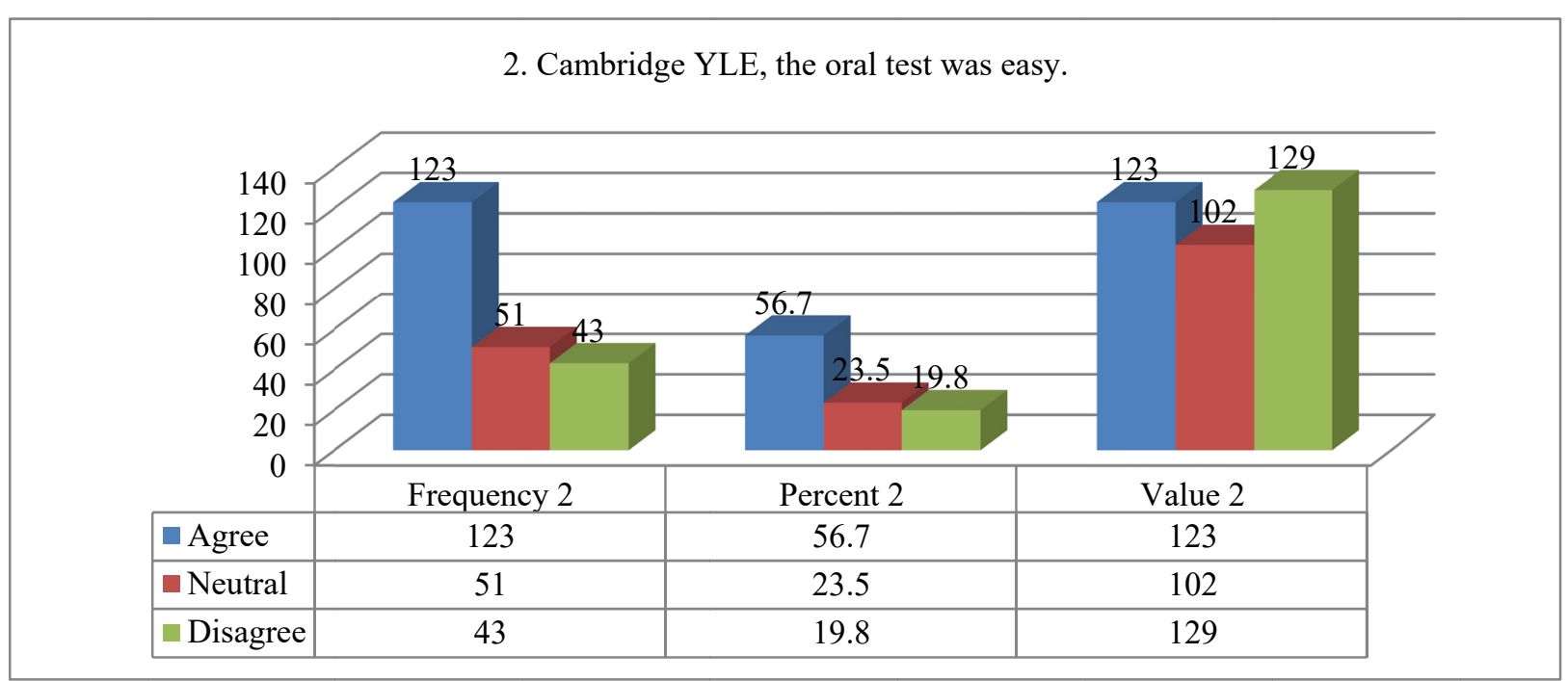

Table 3: $6^{\text {th }}$ Grade illustrates that about $56.7 \%$ of the participants agreed and $19.8 \%$ of the YLE opposed this view. Only fifty-one pupils out of (217) remained neutral. 
Table 4. $6^{\text {th }}$ Grade

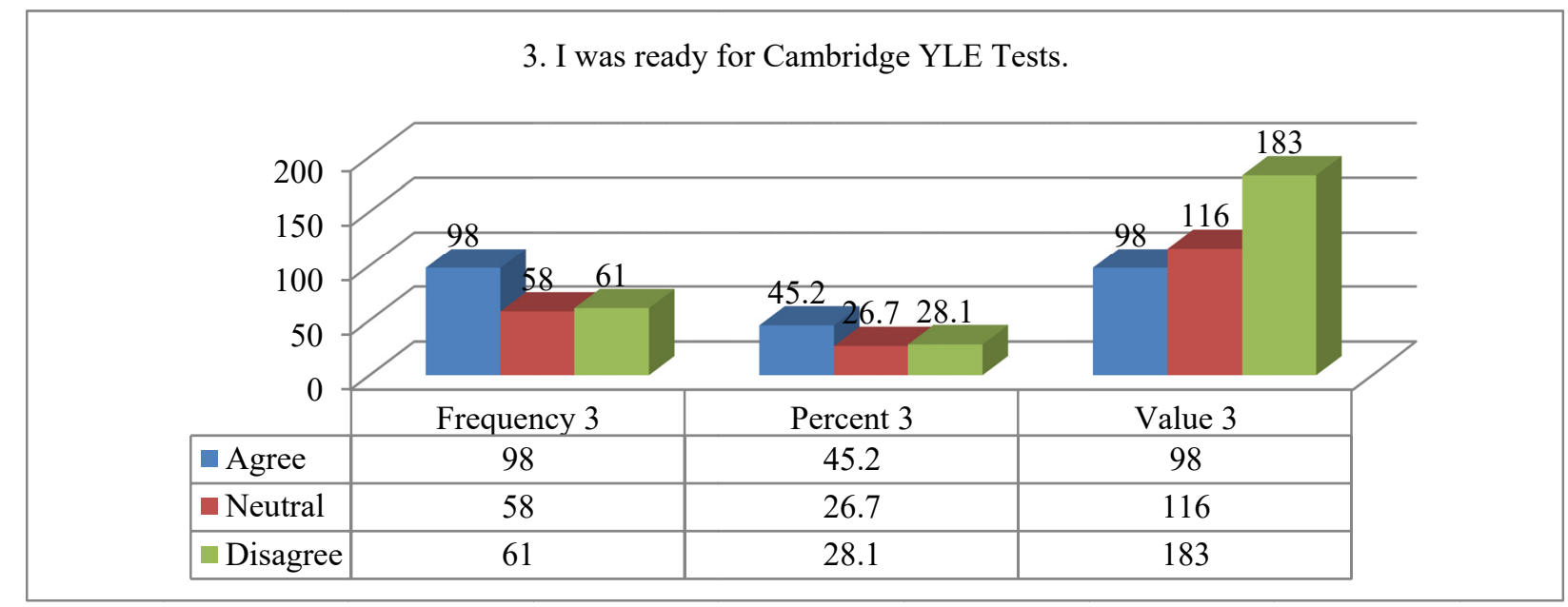

Table 4: $6^{\text {th }}$ Grade shows the readiness of the subjects for Cambridge YLE Tests. About $45.2 \%$ of the responses agreed. About $28.1 \%$ disagreed and $26.7 \%$ were neutral. Moreover, this figure tells something about motivation, and preparation for Cambridge YLE tests might be under the level.

Table 5. $5^{\text {th }}$ Grade

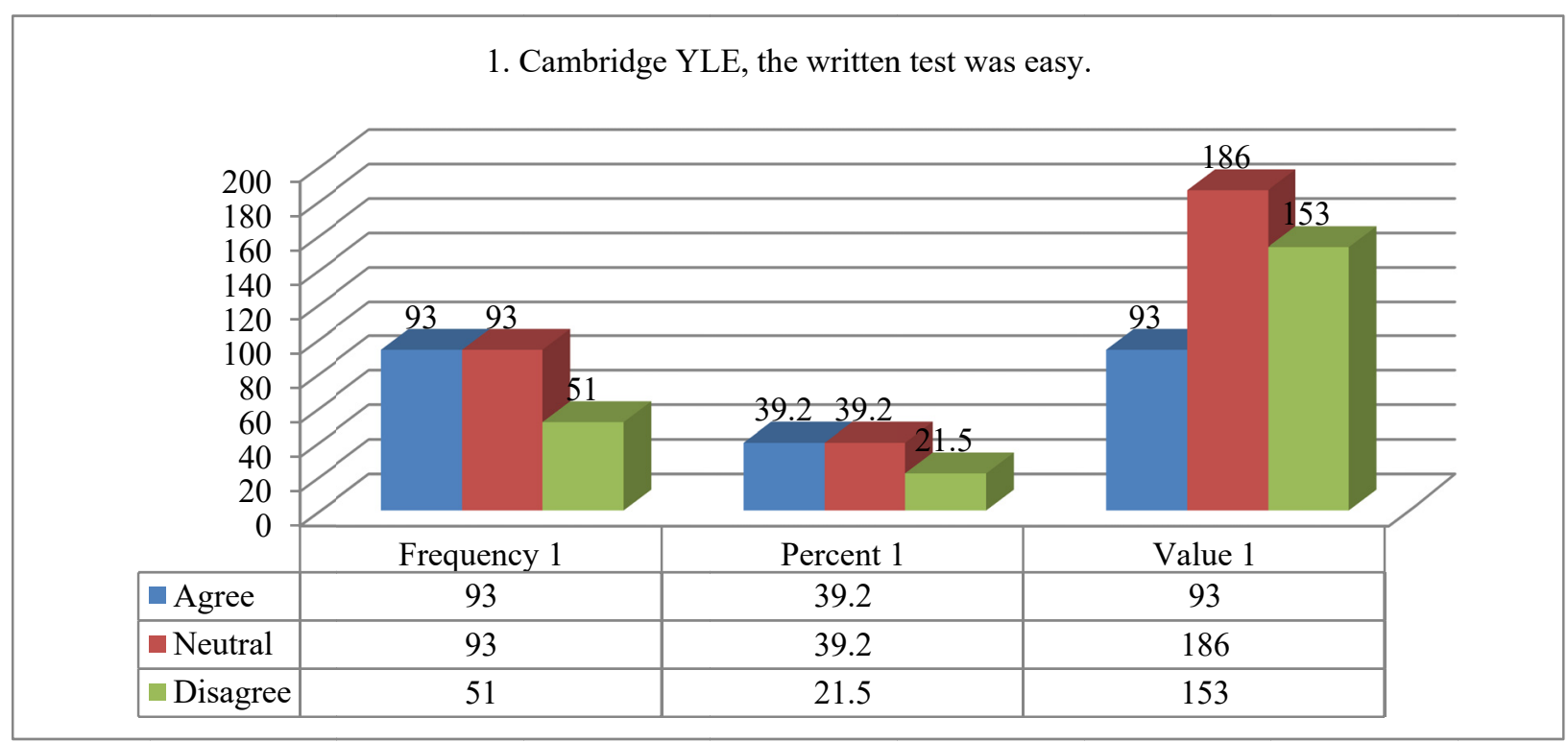

Table $55^{\text {th }}$ Grade shows agree as same as neutral responses in terms of number. It was ninety-three respondents. They agreed that Cambridge YLE the written test was easy. About $21.5 \%$ of the reactions were disagreeing. 
Table 6. $5^{\text {th }}$ Grade

\begin{tabular}{|r|r|r|}
\hline 2. Cambridge YLE, the oral test was easy. \\
\hline \\
\hline
\end{tabular}

Table 6: $5^{\text {th }}$ Grade indicates that more than $56 \%$ of the responses agreed with the easiness of Cambridge YLE's oral test. They represented (133) out of (237) responses. About $17.3 \%$ of reactions disagreed, and $26.6 \%$ reminded neutral.

Table $7.5^{\text {th }}$ Grade

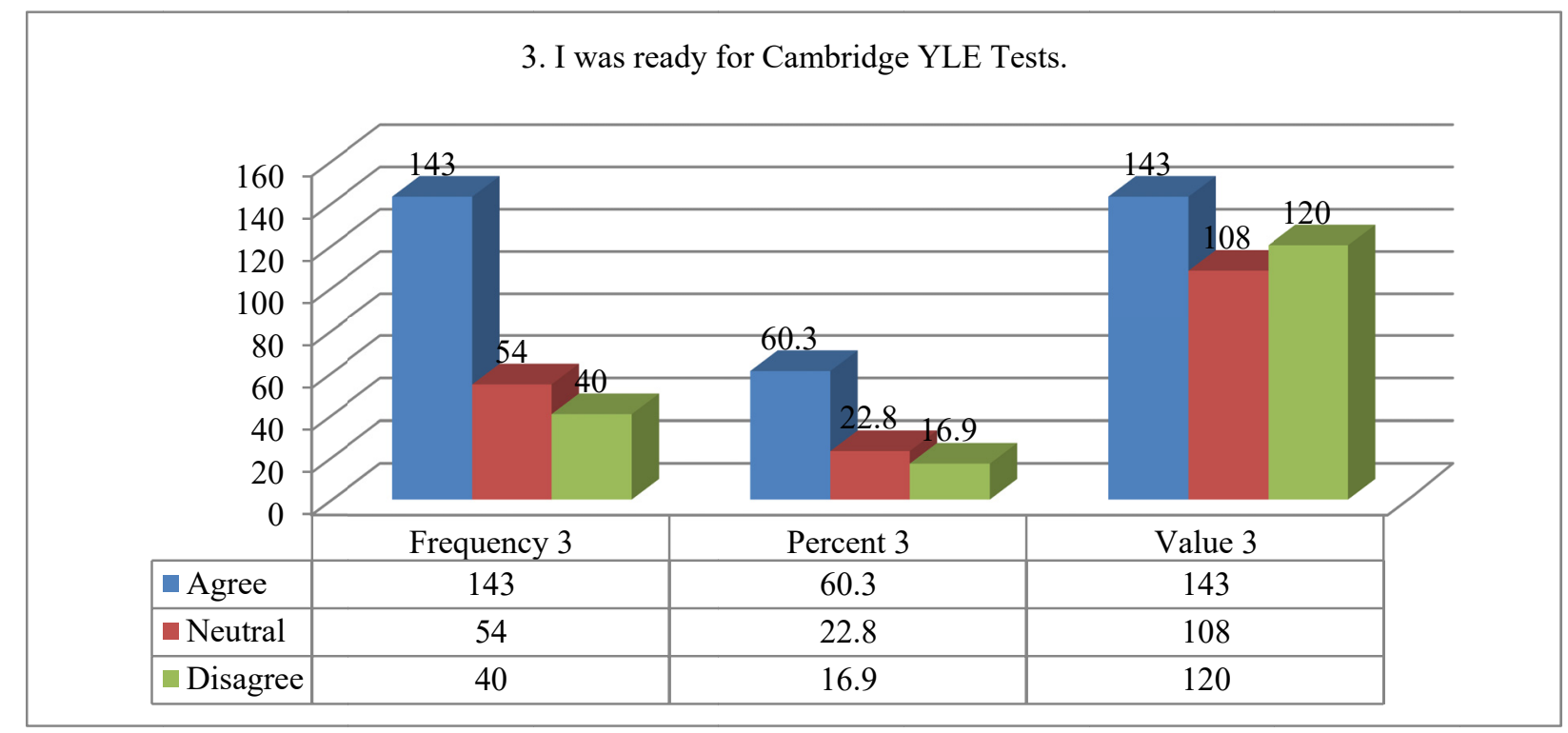

Table 7: $5^{\text {th }}$ Grade shows about $60.3 \%$ of the responses were agreed, and only $16.9 \%$ disagreed that they were ready for Cambridge YLE Tests. About $22.8 \%$ of the responses were neutral. They did not know whether they were prepared or not.

\subsection{Teachers' Interview}

The researcher interviewed seven English language instructors of $\mathrm{fif}^{\text {th }}$ and $\operatorname{six}^{\text {th }}$ grades; Al-Aqsa School. He set up convenient times for each respondent to conduct the interview. Face-to-face meetings were held with the interviewees. Instructors were given pseudonyms; test name plus a number, i.e., Flyer1. The interviews had been transcribed and scanned into PDF files. They saved for later stages of retrieval and summarising. The instructors 
were asked three questions:

a) What did you do for the Cambridge YLE Test?

b) How was your pupils' motivation?

c) How much stress was? Why?

Their answers summarised in Table 8 as follows:

Table 8. Instructors' interview

\begin{tabular}{|c|c|c|c|}
\hline Teacher & focused on & Learners' Motivation & Stress \\
\hline Flyers 1 & $\begin{array}{l}\text { 1. sample papers from YLE site } \\
\text { 2. integrated skills } \\
\text { 3. labouring the textbook } \\
\text { 4. visited various websites. } \\
\text { 5. uploading sample and } \\
\text { providing links on the school's } \\
\text { website, Classera. }\end{array}$ & $\begin{array}{l}\text { 1. The motivation was low. } \\
\text { 2. Learners had no previous } \\
\text { experience of YLE } \\
\text { Note: the instructor gave the } \\
\text { learners instruction of the YLE } \\
\text { tests regulations. }\end{array}$ & $\begin{array}{l}\text { 1. The stress was high. } \\
\text { 2. Pupils lacked interest. } \\
\text { 3. There is not enough time } \\
\text { for each skill, so the } \\
\text { instructor integrated the } \\
\text { skills. } \\
\text { 4. Multilevel classes }\end{array}$ \\
\hline Flyers 2 & $\begin{array}{l}\text { 1. sample papers from YLE site } \\
\text { 2. each skill separately } \\
\text { 3. uploaded the samples } \\
\text { 4. information about YLE test } \\
\text { 5. interactive whiteboard, and } \\
\text { sample version for speaking }\end{array}$ & $\begin{array}{l}\text { 1. The motivation was weak. } \\
\text { 2. There was no practical } \\
\text { cooperation from the school's } \\
\text { administration. } \\
\text { 3. Both learners \& school } \\
\text { administration ignored the test } \\
\text { process. } \\
\text { Note: The instructor hoped } \\
\text { adequate preparation next year. }\end{array}$ & $\begin{array}{l}\text { 1. Stress was high. } \\
\text { 2. Pupils did not care about } \\
\text { the test } \\
\text { 3. that resulted in unplanned } \\
\text { techniques of the analysis. } \\
\text { 4. The instructor worked } \\
\text { hard. }\end{array}$ \\
\hline Flyers 3 & $\begin{array}{l}\text { 1. sample papers from YLE site } \\
\text { 2. skills (reading, writing, } \\
\text { listening \& writing) separately } \\
\text { 3. uploaded everything } \\
\text { concerning the test on Classera } \\
\text { 4. gave them links }\end{array}$ & $\begin{array}{l}\text { 1. The motivation was low. } \\
\text { 2. Essentials were weak, almost } \\
\text { nothing. } \\
\text { 3. Some students were good } \\
\text { Note: The instructor started } \\
\text { from scratch (alphabet). }\end{array}$ & $\begin{array}{l}\text { 1. Stress was average. } \\
\text { 2. Pupils did not care. } \\
\text { 3. The instructor had time } \\
\text { for skills, but the majority } \\
\text { of pupils had no bases. }\end{array}$ \\
\hline Flyers 4 & $\begin{array}{l}\text { 1. sample papers from YLE site } \\
\text { 2. vocabulary \& meaning } \\
\text { 3. tenses \& structure of the } \\
\text { sentence. } \\
\text { 4. practice speaking, sample }\end{array}$ & $\begin{array}{l}\text { 1. The motivation was low \& } \\
\text { some were highly motivated. } \\
\text { Note: Motivation depends on } \\
\text { students themselves, teacher, } \\
\text { parents and school's } \\
\text { administration. }\end{array}$ & $\begin{array}{l}\text { 1. Stress was high pressure. } \\
\text { 2. The teacher believed that } \\
\text { he was responsible for } \\
\text { pupils should take high } \\
\text { marks. } \\
\text { 3. There is no connection } \\
\text { between the textbook \& } \\
\text { YLE test }\end{array}$ \\
\hline Movers 1 & $\begin{array}{l}\text { 1. sample papers from YLE site } \\
\text { 2. uploaded photocopy on } \\
\text { Classera } \\
\text { 3. vocabulary \& spelling } \\
\text { 4. practice speaking } \\
\text { 5. practice listening }\end{array}$ & $\begin{array}{l}\text { 1. The motivation was varied; } \\
\text { high \& low. } \\
\text { 2. learners were not interested } \\
\text { in Tests. } \\
\text { 3. Some were highly } \\
\text { motivated. } \\
\text { Note: Motivation upraising was } \\
\text { a challenge. }\end{array}$ & $\begin{array}{l}\text { 1. Stress was average. } \\
\text { 2. The teacher thought he } \\
\text { was responsible for the test } \\
\text { result. } \\
\text { 3. Low motivated pupils and } \\
\text { careless. }\end{array}$ \\
\hline
\end{tabular}


1. sample papers from YLE site

2. uploaded papers in Classera

Movers 2 3. links_videos for speaking 4. Vocabulary \& textbook

1. sample papers from YLE site

2. integrated skills

Movers 3 3. handing out vocab. List

4. dictation exercises

5. practice test parts
1. The motivation was good.

Note: Although the school sent SMS to the parents, some pupils absented and did not care.
1. The instructor faced challenges such as multiple level classes,

2. Some pupils \& parents did not give tests more care.

1. The majority was motivated
learners.

2. The instructor gave learners full information about the test and its importance.
1. Stress was high.

2. Preparing the pupils for Tests without stop teaching textbook (Wonderful World) was a complicated process.

Table 8 shows all English instructors googled to find something like a guide for YLE Tests. Their teaching methods varied between synthetic and holistic approaches. Two out of seven teachers used integrated skills method while the others focused on each skill separately. They uploaded sample papers from the Cambridge website into school's site; Classera (Note 2). Flyers 1, Flyers 4 and Movers 2 used the textbook.

In contrast, the others did not consider the syllabus they were teaching. They depended on downloading sample papers mainly from the Cambridge assessment site. According to teachers, no one of them searched for test concept and how proficiency tests measured persons' ability. They just run after sample test papers from the Cambridge website. Then they uploaded them into the school's website and practised these papers with their pupils. Therefore, YLE tests had influenced teaching methods to some extent and pushed teachers to focus on test techniques.

As stated by the interviewees, learners' motivation was low at $6^{\text {th }}$ Grade, whereas the motivation varied between low and good at $5^{\text {th }}$ Grade. Movers 1 said that pupils were not interested in the YLE Tests, and Flyers 1 confirmed that the pupils had no idea or experience about Cambridge YLE Tests. Flyers2 noted, "Next year I hope effective preparation". Movers 1 mentioned that uprising pupils' motivation was a challenge. Flyers4 assumed that motivation depended on teachers, parents, school's administration, and pupils themselves. Although Al-Aqsa School sent SMS to the parents, some pupils absented themselves from the test and did not care about it.

According to participants, the stress of English language instructors was high pressure due to the following:

1) Multiple-level classes

2) Pupils' motivation under the average.

3) Pupils Lacked basic knowledge of the English language.

4) No one cared; school administration, majority of pupils, parents were meant.

5) Inadequate preparation for YLE tests.

6) Some instructors felt that they were responsible for pupils should obtain high marks.

7) Textbooks (Wonderful World series) should be taught alongside pupils' preparation for YLE.

8) Lack of time, Flyers1 said, "There is no enough time for each skill, so l integrated the skills."

9) Cambridge YLE tests were not considered as an initial assessment. They were taken into account as an additional task.

\subsection{Observation}

The researcher was a standby YLE testees. He was YLE tests coordinator in the schools. He was responsible for organising pupils before entering the oral tests rooms. He observed pupils' behaviour before entering the testing room as:

1) They were restless inside the waiting room.

2) They were frustrated. Frustrations could be observed in learners' chatting and their questions in the waiting room. Most of them frequently asked questions:
a) "Is the tester an angry person?"
b) "Is he, Muslim?" 
c) "Does he speak Arabic?"

d) "Is the test easy or difficult?"

e) "Why do we have Cambridge tests?"

3) Some pupils escaped (intended to get away) from the waiting rooms.

4) Some young learners hesitated to take the oral test.

5) At break time, pupils resisted leaving the waiting room.

6) Children had a preconceived idea that the oral test was not easy.

7) Twenty children absented from written and oral tests.

Those above observations showed that pupils were in the resistance zone ( $R$-Zone) rather than congruence zone (C-Zone). The coordinator tried to make them calm down by responding to their frequent questions. They were used to written tests_ pen-paper tests. The oral form was brand-new and somehow strange to them. Pupils' questions about YLE, oral test and the testers reflected their fear. Fear test dominated their verbal and action behaviour.

\section{Discussion}

Decision maker's beliefs about international proficiency tests and decentralisation of Saudi School Certificate might be reasons, which encouraged private schools such as Al-Aqsa School looking for alternative standardised measurement. Moreover, they chose their English syllabuses that were available in the international market. Al-Aqsa School used Cambridge Assessment, i. e., YLE tests as a tool to tout parents and to gain good reputation (report); in the Ministry of Education. The School provided free YLE tests to its pupils. For-profits the School benefited all its young learners and had increased levels of educational achievement (Sahlgren, 2010). Those tests caused confusions and high pressure. Al-Aqsa School should have a follow-up of the effect of these tests on both pupils' motivation and their teacher's stress. Close attention to the formative and summative tests is required. Attainment tests and YLE tests were held at the same time. A complicated situation might be summarised as:

1) Learner's confusions:

a) Achievement tests and proficiency tests took place at the same time.

b) Frustrations before the tests, pupils were asking questions about the types of questions and the testers.

c) The researcher observed pupils resisted and hesitated to enter the test's room.

2) High pressure on teachers:

a) Their reputation depends on the results of the test.

b) As a result, they taught test techniques. The techniques became an end of themselves.

c) They work individually to secure their jobs_no collaborative work.

\section{Conclusion}

1) Lack of inner motivation to take YLE might be due to the weak of instrumental motivation to pass the test.

2) The adoption of YLE tests was at the expense of children's motivation.

3) Pupils experienced Fear Test may demotivate them to take a proficiency test in the future.

4) YLE tests were unfair because they did not base on pupils' textbook.

5) Teachers did not have a magic solution. They surfed (googled) the websites in an attempt they would find something for their pupils.

6) Teachers' teaching methods varied between synthetic and holistic approaches.

\section{Recommendation and Suggestions}

This research recommended that there was a need for professional development opportunities and ongoing support. In addition to the School would train English language instructors to motivate and prepare young learners of YLE tests. Some systematic process and collaborative work should be considered so as both the School and learners could benefit from Cambridge assessment. Otherwise, Al-Aqsa School should not administer YLE tests at the primary stage. The alternative yardstick was more standardised academic achievement tests, alongside placement tests at the beginning of the school academic year. The suggestions could be summarised as: 
1) Placement test should take place to locate each pupil in an appropriate area.

2) Collaborative work should be done towards learners' motivation among the school's administrators, parents and teachers.

3) The School should provide in-service teachers' program for YLE Tests.

\section{References}

Al-Seghayer, K. (2014). The Actuality, Inefficiency, and Needs of EFL Teacher-Preparation Programs in Saudi Arabia. International Journal of Applied Linguistics and English Literature, 3(1), 143-151. https://doi.org/10.7575/aiac.ijalel.v.3n.1p.143

Alfaki, I. M., \& Khamis, A. H. A. (2014). Difficulties Facing Teachers in using Interactive Whiteboards in their Classes. American International Journal of Social Science, 3(2), 136-158. Retrieved from http://www.aijssnet.com/journals/Vol_3_No_2_March_2014/16.pdf

Alghamdi, G. A. (2006). Backwash: The Impact of a Core Proficiency Test on the Learning/Teaching Situation: A Case Study. Language and Translation, 19, 1-15.

Ali, J. K. M. (2019). Testing Self-Determination Theory in Conflict-Affected Areas: A Case Study of Yemeni EFL Students. International Journal of English Linguistics, 9(4), 366-375. https://doi.org/10.5539/ijel.v9n4p366

Bentley, K. (2015). CLIL scenarios with young learners. Teaching English to Young Learners: Critical Issues in Language Teaching with 3-12-Year-Olds, 91. Retrieved from 10.5040/9781474257145.ch-006

Broussard, M. (2016). Black Literary Suite: Sports Figures with a Kansas Connection. Retrieved from https://kuscholarworks.ku.edu/bitstream/handle/1808/20314/BLS_2016_SportsFigures.pdf;sequence

Brown, H. D., \& Abeywickrama, P. (2004). Language assessment. Principles and Classroom Practices. White Plains, NY: Pearson Education. https://doi.org/10.4324/9781315717173-46

Deci, E. L., \& Ryan, R. M. (2008). Self-Determination Theory: A macro theory of human motivation, development, and health. Canadian Psychology/Psychologie Canadienne, 49(3), 182-185. https://doi.org/http://dx.doi.org/10.1037/a0012801

Harmer, J. (2007). The Practice of English Language Teaching (4th ed). Harlow: England Pearson Education. https://doi.org/10.1093/elt/ccx060

Hughes, A. (2003). Testing for language teachers. https://doi.org/https://doi.org/10.1017/CBO9780511732980

Ingram, E. (1968). Testing in the Context of a Language Learning Experiment. Language Learning, 18(3), 147-161. https://doi.org/https://doi.org/10.1111/j.1467-1770.1968.tb00228.x

Karrar, K. M. (2007). Lecture Notes: Language Testing. Department of English, Nile Valley University, Sudan.

Khan, I. A. (2011). Challenges of Teaching/Learning English and Management. Global Journal of Human Social Science, 11(8), 69-80.

Liu, A. (2017). Children authoring storybooks: A Narrative approach for children learning a new Language. International Journal of Narrative Therapy \& Community Work, 1, 40-55.

Marshall, S. T. (1984). Educational psychology for the teacher in Africa. London, United Kingdom: Hodder Arnold.

Ryun, J. (n.d.). Jim Ryun Quotes. BrainyQuote.com. Retrieved August 29, 2019, from BrainyQuote.com. Retrieved from https://www.brainyquote.com/quotes/jim_ryun_127356

Sahlgren, G. H. (2010). Schooling for Money: Swedish Education Reform and the Role of the Profit Motive. Economic Affairs, 31(3), 28-35. https://doi.org/10.1111/j.1468-0270.2011.02112.x

Siddiek, A. G. (2010a). Evaluation of the Sudan School Certificate English Examinations. English Language Teaching, 3(2), 37-47. https://doi.org/10.5539/elt.v3n2p37

Siddiek, A. G. (2010b). The Impact of Test Content Validity on Language Teaching and Learning. Asian Social Science, 6(12), 133-143. https://doi.org/10.5539/ass.v6n12p133

Siddiek, A. G. (2011). Standardisation of the Saudi Secondary School Certificate Examinations and Their Anticipated Impact on Foreign Language Education. International Journal of Humanities and Social Science, 1(3), 57-64. https://doi.org/10.2139/ssrn.3185841 
Siddiek, A. G. (2012). The General Certificate Examinations as a Tool of Measurement \& Quality Control of Educational Objectives in Some Arab Countries with Special Reference to Saudi Arabia. American International Journal of Contemporary Research, 2(5), 136-148.

Williams, M., \& Burden, R. L. (1997). Psychology for Language Teachers: A Social Constructivist Approach. https://doi.org/https://doi.org/10.1016/S0889-4906(01)00011-4

\section{Web pages}

https://www.cambridgeenglish.org/images/153612-yle-handbook-for-teachers.pdf

https://www.investopedia.com/terms/a/aptitude-test.asp

https://www.brainyquote.com/quotes/jim_ryun_127356

https://www.qiyas.sa/en/Pages/default.aspx

http://www.alaqsa.edu.sa

\section{Notes}

Note 1. Qiyas is the National Center for Assessment of Higher Education in KSA. Universities consider 70\% of Qiyas grades.

Note 2. Classera is Al-Aqsa Website_e-learning platform for its Students, www.alaqsa.edu.sa

Appendix A1

\begin{tabular}{llll}
\hline & Overall length & Number of tasks/parts & Number of items \\
\hline Movers & & & \\
Listening & Approx 25 mins & 5 & 25 \\
Reading \& Writing & 30 mins & 6 & 35 \\
Speaking & $5-7$ mins & 4 & - \\
Total & Total approx. 1 hour 2 mins & \\
\hline https://www.cambridgeenglish org/images/153612-yle-handbook-for-teachers.pdf
\end{tabular}

https://www.cambridgeenglish.org/images/153612-yle-handbook-for-teachers.pdf

Appendix A2

\begin{tabular}{llll}
\hline & Overall length & Number of tasks/parts & Number of items \\
\hline Flyers & & & \\
Listening & Approx 25 mins & 5 & 25 \\
Reading \& Writing & 40 mins & 7 & 44 \\
Speaking & $7-9$ mins & 4 & - \\
Total & Total approx. 1 hour 14 mins & \\
\hline \multicolumn{2}{l}{ https://www.cambridgeenglish.org/images/153612-yle-handbook-for-teachers.pdf }
\end{tabular}

Appendix B. Learners' questionnaire

\begin{tabular}{llll}
\hline Statement & Agree & Neutral & Disagree \\
\hline Cambridge YLE oral test was easy. & & & \\
Cambridge YLE written test was easy. & & & \\
I was ready for the Cambridge YLE Test. & & & \\
\hline
\end{tabular}




\section{Copyrights}

Copyright for this article is retained by the author(s), with first publication rights granted to the journal.

This is an open-access article distributed under the terms and conditions of the Creative Commons Attribution license (http://creativecommons.org/licenses/by/4.0/). 